\title{
Paediatric RCC with sarcomatoid variation: a rare entity
}

\author{
Anuj Mahajan ${ }^{1 *} \mathbb{D}$, Prashanth Adiga ${ }^{1}$, Vivek Pai $^{1}$ and Keerthi Raj ${ }^{2}$
}

\begin{abstract}
Background: Malignant renal masses in paediatric age group are mostly Wilms'tumour. RCC is very rare in this age group, papillary variant being the most common. Sarcomatoid variation occurs in 5\% of adult RCC, while it is extremely rare in children. No treatment protocol exists in the management of paediatric RCC.

Case presentation: Here, we present a case of 10-year-old female who presented with left flank mass. Radical nephrectomy was done which showed clear cell carcinoma with sarcomatoid variant on histopathological examination.

Conclusion: RCC with sarcomatoid variation can occur in children. However, further studies and long-term follow-up are needed for formulating a treatment protocol and prognostication factors for the same.
\end{abstract}

Keywords: Paediatric RCC, Non-Wilms'tumours, Radical nephrectomy in children

\section{Background}

Renal cell carcinoma (RCC) is the most common renal malignant neoplasm in adults, accounting for $2-3 \%$ of all the adult malignancy. However, it occurs rarely in children with an incidence of $0.1-0.3 \%$ of all the neoplasm and $1.8-6.3 \%$ of all the malignant renal tumours $[1,2]$.

The literature on paediatric RCC is lacking with no adequate therapy defined. Surgery for a localized tumour is the standard, while the role of regional lymphadenectomy, adjuvant radiotherapy or chemotherapy is still controversial and various regimens have showed minimal activity in clinical trials [1].

Biological behaviour and prognostic factors are not well known in children with no definite protocols. The most common pathological subtype in children is papillary carcinoma as compared to clear cell carcinoma in adults. Sarcomatoid variant is extremely rare variant in adult RCC accounting for only $5 \%$ of the cases [3].

\footnotetext{
${ }^{*}$ Correspondence: mahajan1612@gmail.com

1 Department of Urology, Father Muller Medical College and Hospital, Mangalore, Karnataka, India

Full list of author information is available at the end of the article
}

There is not much literature on the prevalence of sarcomatoid variation in paediatric RCC.

Here, we present a case of 10 -year-old child presenting with an asymptomatic left flank mass.

\section{Case presentation}

A 10-year-old female was referred to our department with complaints of an asymptomatic left flank mass. History was unremarkable with no haematuria, flank pain, fever or episodes of increased urine output associated with pain. There was no history suggestive of hereditary syndrome in the child or family.

On examination the child showed normal developmental milestones with no genito-urinary anomalies and organ asymmetry. There was a large mass palpable in the left flank with the superior border going below the costal margin, medial border towards the umbilicus and inferior border about $9 \mathrm{~cm}$ below the costal margin.

Ultrasound abdomen was in concurrence with the examination finding showing a large renal mass about $10 \times 9 \mathrm{~cm}$ in size.

The patient was then taken up for a contrast-enhanced computed tomography which showed a large circumscribed heterogeneously enhancing solid mass lesion 
measuring $11.0 \times 11 \times 9 \mathrm{~cm}$ in the upper and midpole of the left kidney with few tiny calcific foci (Fig. 1).

Anteriorly the lesion was compressing the distal transverse colon and abutting the abdominal wall. Dilated gonadal vein was present on the left side. There was no evidence of tumour extension in the renal vessels. There was no lymphadenopathy.

CT chest was normal with no evidence of any metastatic lesions.

In view of the age of the patient, Wilms' tumour was kept as a differential diagnosis. Wilms' tumour of this size would have needed neo-adjuvant chemotherapy. Therefore, FNAC was done which was suggestive of clear cell RCC.

The patient was taken up for left radical nephrectomy with regional lymphadenectomy. Intra-op the renal capsule was intact with no renal vein or IVC thrombus. There was no regional lymphadenopathy (Fig. 2).

Histopathological analysis revealed a $10 \times 10 \times 5.5 \mathrm{~cm}$ renal clear cell carcinoma in the upper and midpole of the kidney (Fig. 3). Ureteric and pelvicalyceal system margins were free of tumour with no lymphovascular or perineural invasion. There was, however, sarcomatoid differentiation of the tumour (Fig. 4).

Ten lymph nodes were sampled, none of which showed involvement with tumour.

The pathological staging of the tumour was T2aNOM0 according to AJCC 8th edition.

Post-op the patient did well. Drain and catheter were removed on post-op days 2 and 4, and the patient was discharged on post-op day 6 .

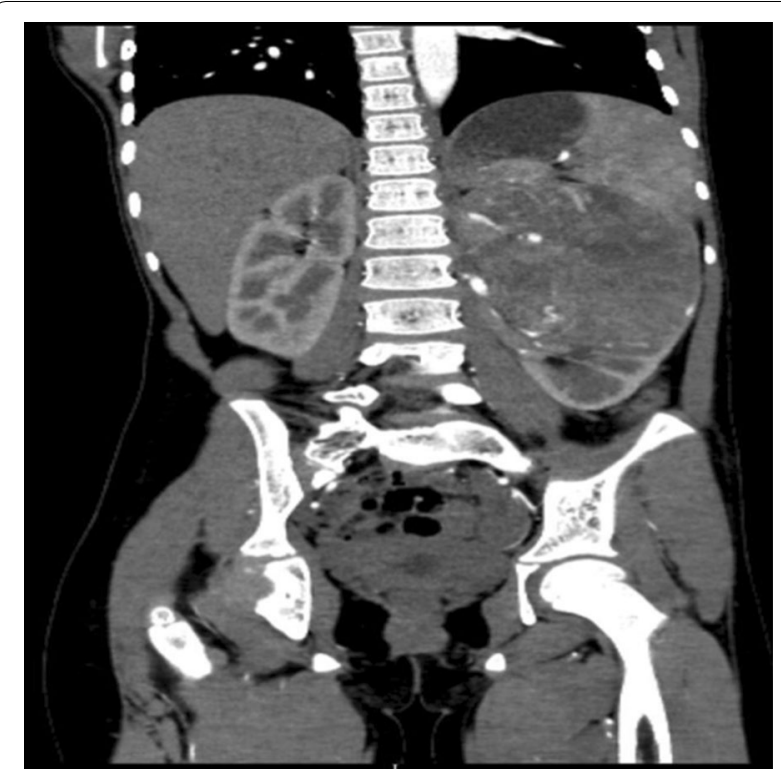

Fig. 1 CT abdomen showing a large left renal mass

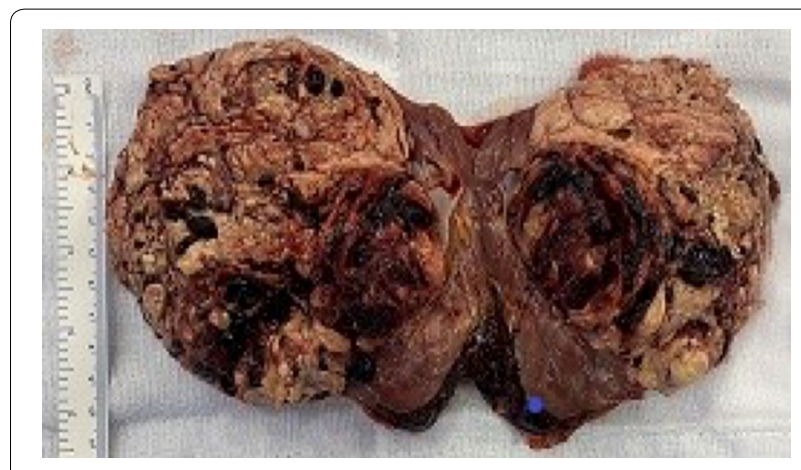

Fig. 2 Gross specimen after radical nephrectomy

On follow-up after 2 months, the patient was well with a normal kidney function and no abnormality on abdominal ultrasound.

\section{Discussion}

The most common renal malignancy in childhood is Wilms' tumour with renal cell carcinoma (RCC) being very uncommon accounting for $2-5 \%$ of all paediatric renal malignancies [4]. Renal cell carcinoma originates within the epithelium of renal tubules and may be of papillary, clear cell, chromophobe and oncocytoma morphology [5].

A large number of paediatric RCC patients have a hereditary disorder like von Hippel-Lindau disease or

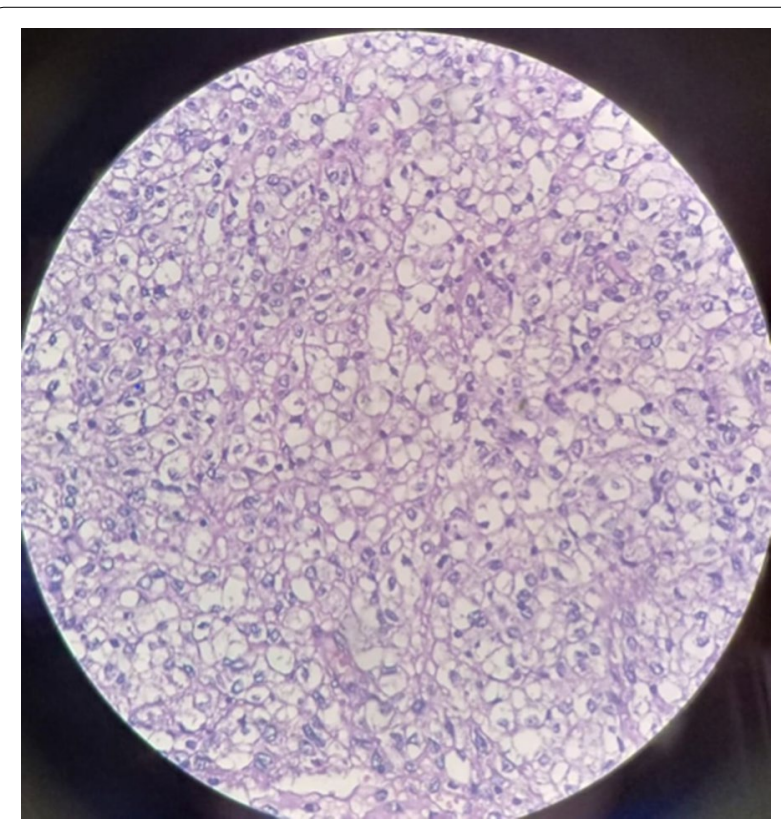

Fig. 3 Microscopic picture showing clear cell carcinoma 


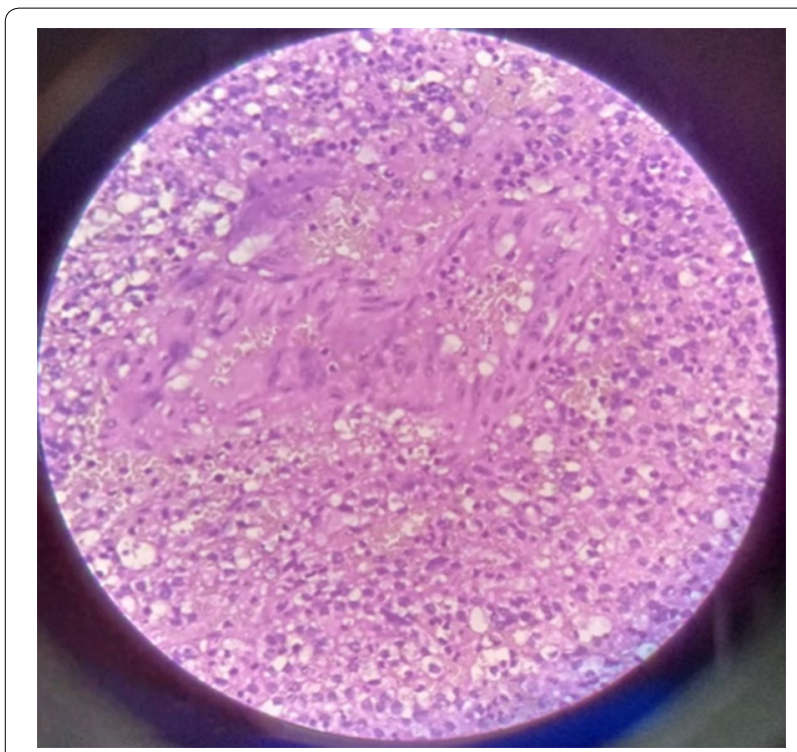

Fig. 4 Microscopic picture showing sarcomatoid variation

have a prior history of undergoing treatment for such as Wilms' tumour or neuroblatsoma [6].

Therefore, paediatric RCC is mostly a second malignancy in children who have survived previous diseases, possibly from radiation or chemotherapy [6].

Paediatric RCC is mostly papillary type with high survival rate after treatment [5]. Predictors of poor survival like sarcomatoid differentiation, perivascular and perineural invasion are extremely rare. Radical nephrectomy with lymphadenectomy is the primary treatment modality for paediatric RCC as no studies currently support an increase in survival after the use of adjuvant or neo-adjuvant chemotherapy or radiation therapy [4].

Most patients present with an asymptomatic flank mass, while some may present with haematuria, pain and/or abdominal mass [6]. As per Children Oncology Group (COG), the use of imaging is very important in the initial assessment of paediatric RCC [6]. An ultrasound can detect a renal lesion, and a contrast-enhanced CT imaging is used to assess tumour size, extension of the mass, enhancement pattern, the presence of calcification (suggestive of RCC), lymph node enlargement, vascular invasion, neo-vascularity, the presence of an ipsilateral or contralateral lesion, and for identification of metastatic disease [6].

The most common differential diagnosis of a renal mass in a child is Wilms' tumour with RCC occurring rarely. Both types of renal malignancies are best treated by surgical resection as a first step. The benefit of adjuvant therapy in case of paediatric RCC is still under study.
Five-year survival rate for patient with stage I is higher than $90 \%$ and $50-80 \%$ for patients with stage II and III and only $9 \%$ for patients with stage IV.

There is not much literature about the presence of sarcomatoid differentiation in paediatric age group, and this was the first such case at our institute.

\section{Conclusion}

In conclusion, experience with paediatric RCC is limited and further studies are necessary to develop a standard therapeutic strategy.

\section{Abbreviations \\ RCC: renal cell carcinoma; CT: computed tomography; AJCC: American Joint Committee on Cancer.}

\section{Acknowledgements}

Not applicable.

\section{Authors' contributions}

All authors have read and approved the manuscript. AM contributed to concepts, literature search, manuscript preparation and manuscript editing. PA contributed to design, definition of intellectual content, data acquisition, manuscript editing and manuscript review and is the guarantor. VP contributed to design, literature search, data analysis and manuscript review. KR performed data acquisition, data analysis and manuscript preparation.

\section{Funding}

No source of funds.

\section{Competing interests}

The authors declare that they have no competing interests.

\section{Availability of data and material}

Data about the patient are obtained from case record.

\section{Ethical approval and consent to participate}

Taken from institutional ethics committee.

\section{Consent for publication}

Written informed consent to publish this information has been obtained from parent and/or legal guardian of the study participant.

\section{Author details}

${ }^{1}$ Department of Urology, Father Muller Medical College and Hospital, MangaIore, Karnataka, India. ${ }^{2}$ Department of Surgery, Father Muller Medical College and Hospital, Mangalore, Karnataka, India.

Received: 14 September 2020 Accepted: 27 November 2020 Published online: 14 December 2020

\section{References}

1. Indolf P, Terenziani M, Casale F, Carli M, Bisogno G, Schiavetti A et al (2003) Renal cell carcinoma in children: a clinicopathologic study. J Clin Oncol 21:530-535

2. Varan A, Akyuz C, Sari N, Buyukpamuu N, Calar M, Buyukpamuku M (2007) Renal cell carcinoma in children: experience of a single center. Nephron Clin Pract 105:58-61

3. Cheville JC, Lohse CM, Zincke H et al (2004) Sarcomatoid renal cell carcinoma: an examination of underlying histologic subtype and an analysis of associations with patient outcome. Am J Surg Pathol 28:435-441 
4. Zhuge Y, Cheung MC, Yang R et al (2010) Pediatric non-Wilms' renal tumors: subtypes, survival, and prognostic indicators. J Surg Res 163:257-263

5. Morabito RA, Talug C, Zaslau S et al (2010) Asymptomatic advanced pediatric papillary renal cell carcinoma presenting as a pulmonary embolus. Urology. 76(1):153-155

6. Downey RT, Dillman JR, Ladino-Torres MF et al (2012) CT and MRI appearances and radiologic staging of pediatric renal cell carcinoma. Pediatr Radiol 42:410-417

\section{Publisher's Note}

Springer Nature remains neutral with regard to jurisdictional claims in published maps and institutional affiliations.

\section{Submit your manuscript to a SpringerOpen ${ }^{\odot}$ journal and benefit from:}

- Convenient online submission

- Rigorous peer review

- Open access: articles freely available online

- High visibility within the field

- Retaining the copyright to your article

Submit your next manuscript at $\boldsymbol{\nabla}$ springeropen.com 